\title{
Lead emissions from open burning of artillery propellants
}

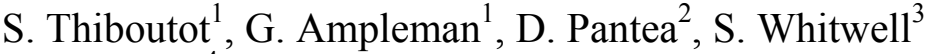 \\ $\&$ T. Sparks ${ }^{4}$ \\ ${ }^{1}$ Defence R\&D Canada, Valcartier, Canada \\ ${ }^{2}$ Directorate Ammunition \& Explosives Management and Engineering, \\ Canada \\ ${ }^{3}$ Director Land Equipment Program Staff, Canada \\ ${ }^{4}$ Directorate Ammunition \& Explosives Regulation, Canada
}

\begin{abstract}
Military live fire artillery training involves the accumulation and subsequent destruction of excess propellants. In the past, the charges were open burned directly on the soil surface, which led to the accumulation of 2,4-dinitrotoluene, nitroglycerine and lead in the surface soil. To prevent this, a burn table was developed for the safe and controlled disposal of excess propellants. While the use of the burn tables eliminated the impacts to the soil and groundwater, the potential emission of lead into the atmosphere was still of concern. Lead foils are used in propellant charges as a de-coppering and gun re-plating agent and are sewn directly to the propelling charge cloth bags. Prior to the burning process, the lead foils are not separated from the propellant, since their removal would involve a tedious and lengthy handling process as well as a high risk of developing static electricity and propellant ignition. Given that the lead foils are left inside the propellant bags during the burning process, questions on how much lead could potentially be released into the atmosphere were raised. In order to answer these questions, a lead mass balance trial was conducted to assess the amount of lead remaining on the burn table following the open burn process. This option was preferred to the measurements of lead in the air emissions, due to the challenges resulting from the intense combustion, high flame height and rapid dilution of the plume. The trial involved 19 burns using three types of propellants: M1 and BT19 for $105 \mathrm{~mm}$ guns and M6 for $155 \mathrm{~mm}$ guns. All burns were done in duplicates, with and without lead. Following the burns, residues
\end{abstract}


were collected and segregated using a decantation technique and fractions were sent to an external laboratory for lead analysis. The results indicated that lead remains in the burn trays in a proportion of $77 \%$ or in the soils profile near the destruction point $(21 \%)$ to reach a total proportion of $98 \%$. This paper will present the lead mass balance results for three representative propellants and will demonstrate that lead is not vaporized but mostly contained in and around the burning tables

Keywords: lead emissions, open burning, gun propellants, artillery live-firing.

\section{Introduction}

Live fire training with various weapons is a key component of military readiness and all NATO countries possess military training ranges measured in thousands of square kilometres where various munitions calibres are routinely fired. In particular, artillery howitzer guns such as the Canadian $105 \mathrm{~mm} \mathrm{C} 1$ gun use a propelling charge system composed of multiple charge bags to fire projectiles at the required range, as illustrated in figure 1.

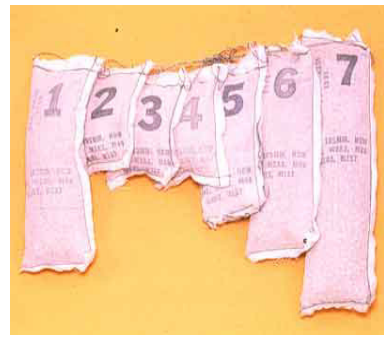

Figure 1: $\quad$ Propellant in multiple charge bags used in $105 \mathrm{~mm}$ artillery guns.

The number of charge bags being used during the live firing depends on the distance to the target. The firing is typically conducted using the least amount of charge bags in order to minimize the wear and tear on the barrel and the gun and to avoid ricochet. Furthermore, the safety templates of most artillery ranges do not allow the firing at full charge. This generates large quantities of excess propellant bags that are accumulated at the gun position. Following an artillery exercise, discarded excess propelling charges are burned on the soil surface or on snow/ice in the winter, near the gun position, just after the gun is moved to its next firing position. This procedure was used in the past because the propellant was judged unsafe to move and store. Most of the propellants used in artillery guns in NATO countries are defined as single $(\mathrm{NC})$, double (NC-NG) or triple base (NC-NG-NQ) propellants and are based on nitrocellulose (NC), which represents more than $80 \% \mathrm{w} / \mathrm{w}$ of the propellant formulations. The propellants tested in this study were all single base propellants, composed mostly of NC plasticized with 2,4-dinitrotoluene (10\% 2,4-DNT), stabilizing products and flash reducing agents. Lead foils are also included in the propelling charges, as it plays a role of de-coppering and gun re-plating agent. Artillery rounds have a 
copper driving band to improve the external ballistics and the use of lead helps in removing excess copper break up from the guns. Moreover, lead is well known to preserve the lifetime of guns, as it minimizes greatly the friction and its erosion.

In the past decade, Canada and the United States developed cutting-edge expertise in the characterization of Ranges and Training Areas (RTAs) for the deposition of munitions constituents and the study of the environmental fate of energetic materials (EM) [1-8]. Major environmental issues were identified and amongst them, the burning of excess propellant bags on the surface soils has proven to be a major source of soil and groundwater contamination. Specific studies were conducted to measure the deposition of residues on the soil surface from field expedient burning of propellants [9, 10]. It was demonstrated that high concentrations of 2,4-DNT and lead resulted from this activity.

In Canada, the open burning (OB) of propellant was a regular activity associated with the firing of artillery guns, namely the 105 and the $155 \mathrm{~mm}$ Howitzer guns. In recent years, the development of Modular Artillery Charge Systems (MACS) for the $155 \mathrm{~mm}$ gun has virtually eliminated the need for disposal of discarded propelling charges. However, the OB of propelling charge increments will remain for years to come for the $105 \mathrm{~mm}$ ammunition guns and until the current stock of incremental charges for the $155 \mathrm{~mm}$ Howitzer ammunition is exhausted. This situation mandated the development of an alternative safe and environmentally friendly destruction method for the excess propelling charges and for the whole charges at the end of their service life. An assessment of the potential options for the replacement of field expedient OB of propellant was accomplished and various options were analysed. The recycling of the excess artillery propellants was considered both for military or civilian applications (e.g. mining industry), but was abandoned due to the unknowns related to the lot and age of the propellants. NC degrades slowly with time and its degradation by-product can lead to auto-ignitions of the propellants. Therefore its re-use cannot be feasible, as the lot variability greatly increases the risks of auto-ignitions. Its destruction in specialized incinerators equipped with stack emissions treatments would represent the best option, but due to limitations imposed by the transport of propellants and costs, it is not a viable option at this time.

A review of the literature showed that very few documents are dedicated to the characterization of former burning sites, to guidelines for permitting OB and to the development of solutions for the OB of propellant [11-13]. Nothing published to date brings a sustainable solution to field expedient OB. This problem has to be dealt with in most of the NATO countries that need to safely destroy excess artillery propellants. In order to replace field expedient OB by a cost effective, safe and environmental OB process, Defence Research and Development Canada - Valcartier (DRDC Valcartier) developed a burning table for the open burning of discarded excess artillery charge.

In Canada, since 2010, the open burning was banned and the use of the tables replaced the field expedient burning of the propellant charges on soils and snow/ ice. The table allows the safe destruction of $200 \mathrm{~kg}$ of excess charge bags per 
burn and leads to a $99.5 \%$ mass reduction. The design ensures a safe process and burn residues can easily be collected and treated as hazardous materials. The gaseous emissions emitted were predicted and monitored during one trial. Gaseous emissions were investigated using a thermo-dynamical code and air sampling. The main combustion products were carbon dioxide, nitrogen and water, with near detection limits for carbon monoxide and ammonia and a few VOCs. Lead was detected only in one event out of four, at low concentrations $\left(8 \mathrm{mg} / \mathrm{m}^{3}\right)$ [14].

The deployment of the burn tables solved the surface soil and groundwater contamination. However, despite one trial where gaseous emissions were monitored, the air emissions from the open burning process are still of concern. In particular, the emission of lead in the atmosphere from the open burning in the Canadian table needed to be better investigated. The removal of the lead foils in the propellant bags prior ignition was considered but involves the manipulation of the charge bags and, that represents a tedious and lengthy handling process as well as a high risk of developing static electricity that may lead to propellant ignition. The health risks associated to the removal of lead foils prior burning had to be weighed against the environmental risks.

The gases sampling from the open burning of large quantities of propellants represents a great challenge. The intensity of the event, the high temperatures, the size of the plume and its rapid dilution makes the measurements difficult, as illustrated in figure 3. In this figure, you can see the air sampling device on the left hand side of the picture, which was located at the best possible location to catch the plume. By chance, the atmospheric conditions were favourable, and most of the plume came back towards the sampling device afterward. However, the sampling over the flame even if more difficult would have been preferable.

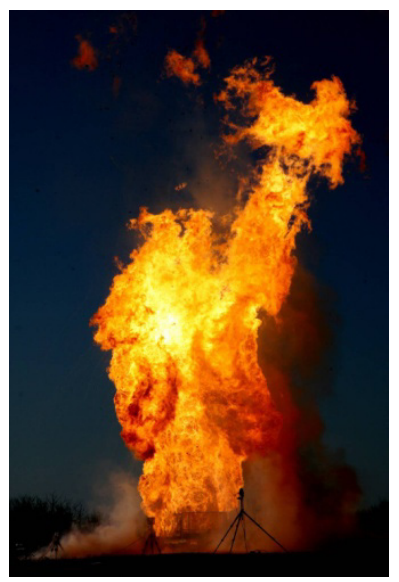

Figure 2: $\quad$ Full burning intensity, with flame height of $40 \mathrm{~m}$.

Due to the complexity associated with the sampling of the air emissions from the open burning of propellants, the determination of lead emissions into the 
atmosphere was determined using mass balance experiments. In other words, burns were conducted with known quantities of lead and the remaining lead in the tables or in their surroundings was carefully measured. The difference represents the lead emitted into the atmosphere.

\section{Trial description/method}

\subsection{Propellants}

Three types of propellants were tested in our study: M1 and BT19 used in 105 $\mathrm{mm}$ and M6 propellant used in $155 \mathrm{~mm}$ artillery howitzer guns. M1 propellant is packaged in seven charge bags, while BT19 in two larger charge bags named zone 1 and 2. M6 is packaged in 5 charge bags and a sixth bag contains $1 \% \mathrm{w} / \mathrm{w}$ of potassium sulfate as a flash reducing agent. Representative formulations of these three propellants are given in Reference 15 and 16: $88 \mathrm{NC}, 8 \%$ 2,4-DNT, $1 \%$ diphenylamine and 3\% dibutyl phthalate. The quantities of lead in each complete propelling charge are respectively: $12,7 \mathrm{~g}, 35 \mathrm{~g}$ and $85 \mathrm{~g}$ for M1, BT19 and M6.

\subsection{Trial}

The trial was conducted in March 2011 at the Canadian forces Ammunition Depot Dundurn. The burns were conducted using four new burn trays disposed in a $50 \mathrm{~m}$ square pattern, on a wide open detonation site where the snow was removed prior the trial. During the trial, high winds were experienced and brought a portion of the burn residues outside of the trays after burns representing the worst case scenario. . The surface and subsurface soils were sandy and allowed the collection of soils samples prior and after the burns, as illustrated in Figure 3.

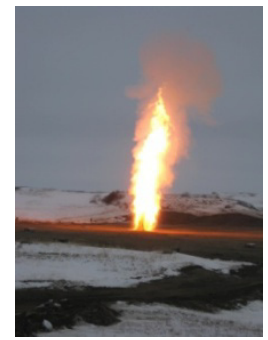

Figure 3: Open burning, dundurn trial.

19 burns were conducted using four clean trays, two were dedicated to "lead burns" and the two others were dedicated to "lead-free burns". Out of the 19 burns, seven were conducted without lead to assess if the burning conditions would be the same and to measure the amount of lead that would remain despite the lead foil removal process. Lead foils are sometimes sewn to the charge bag 
cotton cloth, and the complete removal is almost impossible. EOD specialists carefully removed the lead foils for the "non-lead burns", as illustrated in figure 4. All burns were conducted at the maximum $200 \mathrm{~kg}$ of propellant table loading

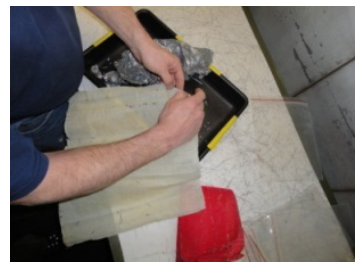

Figure 4: Removal of lead foil in the M6 charge bags.

Six lead containing burns were conducted in replicates. For M1 propellant two burns were done at full charge (charge bags 1 to 7) and two burns were done using only charges bags \# 5, 6 and 7. For BT19, two burns were done at full charge and two burns using zone 2 only. For the M6 propellant, two burns were done at full charge with potassium sulfate $\left(\mathrm{K}_{2} \mathrm{SO}_{4}\right)$ and two without $\mathrm{K}_{2} \mathrm{SO}_{4}$, as its presence was thought to influence the burning conditions. Seven lead-free burns were conducted, including only one replicate. The experimental conditions performed with lead burns were repeated for the lead-free as this: For M1 propellant, one burn was done at full charge and one burn using charge bags \# 5, 6 and 7, for BT19 one burn at full charge and one using zone two only and for M6 three burns with (2 burns) and without (one burn) $\mathrm{K}_{2} \mathrm{~S}_{4}$.

For M1 propellant, the burn at full charge and the burn of charges bags 5,6 and 7 represent two scenarios: the first one being the demilitarisation of the charges at the end of their service life, and the second represents what is normally burned after live firing activities by the artillery users. The burning at full charge and for zone 2 with BT19 represents the same scenarios. For M6, burnings were conducted with and without potassium sulfate, as it is known to diminish the burning efficiency in the tables. The burning temperatures were recorded using thermocouples under the table surface and in the flame, to monitor if the various types of burns would lead to similar burning temperature profiles. After the burns and a cooling period of approximately 20 minutes, the burns residues were carefully collected in metallic pails and sent to our laboratory for further processing. Soils were sampled prior burning around table 3 and 4 where "lead burns" had to be conducted. Soils were sampled using a circular pattern from the center of both tables, from 0 to $5 \mathrm{~m}, 5$ to $10 \mathrm{~m}$ and 10 to $25 \mathrm{~m}$. 100 increments were collected in duplicates prior and at the completion of all burns for each tables. This was done is order to measure how much lead was deposited on the soil surface nearby the destruction point. Due to the high intensity of the burns, it was postulated that a portion of the solid lead would be projected outside the tables, despite the screens that were integrated to the table design.

Lead foils that were removed from charge bags were sent for analysis to know their exact compositions. Burn residues were collected and segregated 
between three fractions: cloths, ashes and metallic fractions. The un-burned cloths were removed manually from the residues and a decantation technique was used to segregate ashes from metallic debris. All fractions were homogenized, and a representative sample was sent for lead analysis to an external laboratory. Figure 5 and 6 shows one example of the lead that was retrieved prior burn and the fractions isolated using our technique.

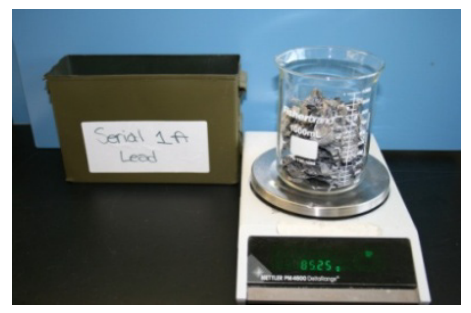

Figure 5: Lead removed from M1 charges.



Figure 6: Fractions isolated from the burn residues.

\section{Results}

The fractions sent to an external laboratory for analysis showed from traces levels to $99 \% \mathrm{w} / \mathrm{w}$ of lead. The percentages of lead recuperated were calculated based on all fractions analysis. The results are presented as the \% of lead that was recuperated in the table and is the summation of the lead recuperated in the metallic, ashes and cloth fractions. Most of the lead was recuperated as metallic lead (metallic fractions). Results of the lead recuperation in the burn trays are presented in table 1, while the results of lead concentrations measured in soils prior and after the burns are presented in Table 2. The mean background soil concentration of lead in the surface soils prior burning was $14 \mathrm{mg} / \mathrm{kg}$. An uncertainty estimated to $10 \%$ is associated with the estimation of lead deposited in the soil surroundings, due to the approximations of the depth of deposition and the soil densities. Between 0.3 and $1 \mathrm{~g}$ of lead was recuperated from the lead-free burn's ashes, due to the difficulty of removing all lead from the bags and from potential cross contamination in the laboratory treatment. The recorded burn temperatures showed similar trends for all burns. 
Table 1: $\quad$ Percentage of lead recuperated in the trays.

\begin{tabular}{|c|c|c|c|c|}
\hline Propellant & \# events & note & $\begin{array}{c}\% \text { of Pb } \\
\text { recuperated }\end{array}$ & \% RDS \\
\hline M1 & four burns & $\begin{array}{c}\text { 2 full charge, 2 with bags } \\
5,6,7 \text { only }\end{array}$ & 96 & 7 \\
\hline M1 & two burns & Full charge & 98 & 8 \\
\hline M1 & two burns & Charge bags 5,6 and 7 only & 94 & 4 \\
\hline BT19 & four burns & $\begin{array}{c}\text { 2 full charge, two using zone } \\
\text { 2 only }\end{array}$ & 100 & 40 \\
\hline BT19 & two burns & full charge & 63 & 4 \\
\hline BT19 & two burns & zone 2 only & 110 & 4 \\
\hline M6 & four burns & $\begin{array}{c}\text { K2SO4, without } \\
\text { K2SO4 }\end{array}$ & 90 & 60 \\
\hline M6 & two burns & without K2SO4 & 40 & 2 \\
\hline M6 & two burns & with K2SO4 & 140 & 40 \\
\hline
\end{tabular}

Table 2: $\quad \mathrm{Pb}$ soil concentrations prior and after burns and total lead deposition per area.

\begin{tabular}{|c|c|c|c|c|c|c|}
\hline $\begin{array}{c}\text { Table \# } \\
\text { and } \\
\text { area } \\
\text { sampled } \\
(\mathrm{m})\end{array}$ & $\begin{array}{c}\text { Contribution to Pb } \\
\text { soil concentrations } \\
(\mathrm{mg} / \mathrm{kg})\end{array}$ & $\begin{array}{c}\text { area } \\
\text { sampled } \\
(\mathrm{m} 2)\end{array}$ & $\begin{array}{c}\text { soil volume } \\
\text { for } 1.0 \mathrm{~cm} \\
(\mathrm{~m} 3)\end{array}$ & $\begin{array}{c}\text { soil density } \\
(\mathrm{kg} / \mathrm{m} 3)\end{array}$ & $\begin{array}{c}\text { mass of soil } \\
(\mathrm{kg})\end{array}$ & $\begin{array}{c}\mathrm{Pb} \\
\text { dispersed } \\
(\mathrm{kg})\end{array}$ \\
\hline T3 0-5 & 1054 & 78.5 & 0.785 & 1600 & 1256 & 1.3 \\
\hline T3 5-10 & 97 & 236 & 2.36 & 1600 & 3776 & 0.4 \\
\hline T3 10-25 & 11 & 1649 & 16.49 & 1600 & 26384 & 0.3 \\
\hline & 4 & 5 & 6 & 7 & 8 & \\
& & & & & & \\
\hline T4 0-5 & 681 & 78.5 & 0.785 & 1600 & 1256 & 0.9 \\
\hline T4-5-10 & 216 & 236 & 2.36 & 1600 & 3776 & 0.8 \\
\hline T4 10-25 & 14 & 1649 & 16.49 & 1600 & 26384 & 0.4 \\
\hline \multicolumn{7}{|c|}{ Total mass of lead deposited } \\
\hline
\end{tabular}

Lead recuperation is almost quantitative for M1 propellant in all types of burns, while it is higher when open burning was done using only zone 2 charge bags for BT 19 propellant, and when keeping $\mathrm{K}_{2} \mathrm{SO}_{4}$ for $\mathrm{M} 6$ propellant. In total for the 12 burns, $14.3 \mathrm{~kg}$ out of $18.6 \mathrm{~kg}$ of $\mathrm{Pb}$ was recuperated in the burn trays $(77 \%)$ and $4 \mathrm{~kg}$ of lead was deposited in the vicinity of the trays $(21 \%)$. This means that $98 \%$ of the lead that was in the charges prior burning was recovered as solid and non-volatilized metallic particles. $60 \%$ of the deposition on the soil surface around the destruction point occurs within a radius of $5 \mathrm{~m}$ from the trays and $85 \%$ within a radius of $10 \mathrm{~m}$. This contamination should be easily dealt with 
if the burning is performed on a concrete pad where grooming and vacuuming will be done after the burns.

\section{Conclusion}

Our mass balance trial represents an innovative study on the emission of lead from the open burning of artillery propellants. While this activity is restricted to military units, it is a worldwide activity conducted by all NATO and other countries that train and fight using artillery guns. Environmental awareness and protection applies to military operations and the Canadian objective in that sense is to reach sustainable military training activities, which will allow military readiness while minimizing or eliminating adverse environmental impacts. In Canada, the use of burn tables for the safe destruction of excess propellants brought protection to the soil surface and water bodies surface from contamination. Our trial was aimed at measuring the potential air emissions of lead from the open burning process.

We demonstrated that "lead-free" burns yielded to similar burning conditions (temperature, time for completion) than leaded burns. Despite the difficulty in containing such violent events such as the intense burning of high energy propellants, we obtained a good reproducibility on all replicates burns, suggesting that our approach leads to representative results.

For M1 propellants, most of the lead ( $\geq 96 \%$ ) was recovered in the burn tray, both for burning either full or partial charges. For BT19, burning at full charge yielded to the recuperation of $63 \%$ of the lead in the tables while $100 \%$ of the lead was recuperated in the tables when burning only zone 2 charges. For M6 charges, $100 \%$ of the lead was recovered when burning with $\mathrm{K}_{2} \mathrm{SO}_{4}$, while only $40 \%$ was recovered when burning without it. In total, $77 \%$ of lead was recovered in the tables and $21 \%$ was recovered on the soil surface near the destruction point. It was estimated that $85 \%$ of the lead deposited outside the table was deposited in the surface soil within a $10 \mathrm{~m}$ radius around the destruction point, in the worst possible meteorological conditions. Our results indicated that the lead foil shape and surface area plays a role on its deposition either in the table or outside it, and that other parameters such as the presence of $\mathrm{K}_{2} \mathrm{SO}_{4}$ or the burning either of the whole or partial charge plays a role on the lead recuperation. Our study indicated that the tables shall be installed over concrete pads of at least 10 square meters at the destruction points, which will enable the collection of the lead particle projections after the burns. Ejected material after burns must be collected and added to the table burn residues for further treatment in an accepted facility.

Most importantly, our trial demonstrated that lead volatilization is not measured to a large extent during open burning artillery propellants and does not represent a threat to the air quality. Contribution of lead to air emission was evaluated to be lower than $2 \%$ during OB propellants. So, the use of the table over a concrete pad for the destruction of excess or end of service life propellants protects soil/water/air environmental receptors. Most of the lead is recuperated as solid material, mostly in the table and in its vicinity. This shall be confirmed out 
of all doubts with a trial that will be held in 2012 in collaboration with the US EPA, where a flyer balloon equipped with various gas and particulate sampling equipment will be flown over representative propellant burnings in Canada.

\section{Acknowledgements}

The Canadian Director Land Environment, the Director Ammunition and Explosive Management and Engineering, the Director Ammunitions and Explosive Regulation and the Sustain Thrust are acknowledged for their financial and logistical support of this project, as well as the Strategic Environmental R\&D Program US funding program (SERDP) for its partial financial support. In particular, we want to acknowledge the help and support of the Canadian Forces Ammunition Dundurn staff, without whom this trial could not have been accomplished.

The authors of this paper carried out this research on behalf of the Government of Canada, and as such the copyright in the paper belongs to the Crown, that is to the Canadian Government.

\section{References}

[1] Jenkins, T.F., Ampleman, G., Thiboutot, S., Bigl, S.R., Taylor, S., Walsh, M. R., Faucher, D., Martel, R., Poulin, I., Dontsova, K.M., Walsh, M.E., Brochu, S., Hewitt, A.D., Comeau, G., Diaz, E., Chappell, M.A., Fadden, J.L., Marois, A., Fifield, R., Quémerais, B., Åimunek, J., Perron, N.M., Gagnon, A., Gamache, T., Pennington, J.C., Moors, V., Lambert, D.J., Gilbert, D., Bailey, R.N., Tanguay, V., Ramsey, C.A., Melanson, L., and Lapointe, M., "Characterization and Fate of Gun and Rocket Propellant Residues on Testing and Training Ranges", Final Report; US Army Engineer Research and Development Center, Cold Regions Research and Engineering Laboratory, Hanover, New Hampshire, U.S., ERDC TR-08-1, January 2008.

[2] Thiboutot, S., Ampleman, G., Lapointe, M.C., Brochu, S., Brassard, M., Stowe, R., Farinaccio, R., Gagnon, A., Marois, A. and Gamache, T., "Study of the Deposition of Ammonium Perchlorate Following the Static Firing of MK-58 Rocket Motors"; Defence Research and Development Canada Valcartier, Quebec, Quebec, Canada, DRDC Valcartier TR 2008-240, October 2008.

[3] Thiboutot, S., Ampleman, G., Marois, A. and Gagnon, A., "Caractérisation des sols de surface du champ de tir et secteurs d'entraînement de la garnison Valcartier"; Defence Research and Development Canada Valcartier, Quebec, Quebec, Canada, DRDC Valcartier TR 2008-190, July 2008.

[4] Ampleman, G., Thiboutot, S., Marois, A., Gagnon, A. and Gilbert D., "Evaluation of the Propellant Residues Emitted During 105-mm Leopard Tank Live Firing and Sampling of Demolition Ranges at CFB Gagetown, 
Canada"; Defence Research and Development Canada - Valcartier, Quebec, Quebec, Canada, DRDC Valcartier TR 2007-515, January 2008.

[5] Thiboutot, S., Ampleman, G., Marois, A., Gagnon, A., Gilbert, D., Tanguay, V. and Poulin, I., "Deposition of Gun Propellant Residues from 84-mm Carl Gustav Rocket Firing”, Defence Research and Development Canada - Valcartier, Quebec, Quebec, Canada, DRDC Valcartier TR 2007408, January 2008.

[6] Diaz, E., Brochu, S., Thiboutot, S., Ampleman, G., Marois, A. and Gagnon, A., "Energetic Materials and Metals Contamination at CFB/ASU Wainwright, Alberta Phase I"; Defence Research and Development Canada - Valcartier, Quebec, Quebec, Canada, DRDC Valcartier TR 2007-385, October 2008.

[7] Pennington, J.C., Jenkins, T.F., Ampleman, G., Thiboutot, S., Brannon, J.M., Hewitt, A.D., Lewis, J., Brochu, S., Diaz, E., Walsh, M.R., Walsh, M.E., Taylor, S., Lynch, J.C., Clausen, J., Ranney, T.A., Ramsey, C.A., Hayes, C.A., Grant, C.L., Collins, C.M., Bigl, S.R., Yost, S. and Dontsova, K., "Distribution and Fate of Energetics on DoD Test and Training Ranges: Final Report"; US Army Engineer Research and Development Center, Cold Regions Research and Engineering Laboratory, Hanover, New Hampshire, ERDC TR-06-13, November 2006.

[8] Brochu, S., Diaz, E., Thiboutot, S., Ampleman, G., Marois, A., Gagnon, A., Hewitt, A.D., Bigl, S.R., Walsh, M.E., Walsh, M.R., Bjella, K., Ramsey, C., Taylor, S., Wingfors, H., Qvarfort, U., Karlsson, R.-M., Ahlberg, M. Creemers, A. and van Ham, N. "Environmental Assessment of 100 Years of Military Training in Canada - The case of Canadian Force Base Petawawa"; Defence Research and Development Canada - Valcartier, Quebec, Quebec, Canada, DRDC Valcartier, DRDC TR 2008-118, October 2009.

[9] Diaz, E., Brochu, S., Poulin, I., Faucher, D., Marois, A., Gagnon, A., "Residual Dinitrotoluenes from Open Burning of Gun Propellant", Defence Research and Development Canada - Valcartier, Quebec, Quebec, Canada, DRDC Valcartier, In publication.

[10] Walsh. M.R., Walsh, M.E. and Hewitt, A.D. "Energetic Residues from the Expedient Disposal of Artillery Propellants"; US Army Engineer Research and Development Center, Cold Regions Research and Engineering Laboratory, Hanover, New Hampshire, U.S., ERDC/CRREL TR-09-8, July 2009.

[11] Jeenigs, B., "Alternative Pan Liners for OB of Propellants", http://p2library.nfesc.navy.mil/P2/_Opportunity_Handbook/15_2.html, 2004.

[12] Kovero, E. and Tervo, J, “Open Burning of Gun Propellants. Specific Methods and Environmental Analysis", Proceedings of the Finex 2002 Seminar, Levi, Kittilia, Finland, September 2002.

[13] Vaselinovica, J., "SALW Ammunition Destruction: Environmental Releases from Open Burning (OB) and Open Detonation (OD) Events", April 2004, SEESAC 2004. 
[14] Savard, S. and Hardy, M.J., "Émissions gazeuse à la bouche d'un canon, rapport d'étape phase II, essai 5, table de brûlage", Report \# 640-PE35480, contrat \# W7701-7-1924/A, Centre de Recherche Industrielle du Québec, Québec, Québec, Canada, Mars 2010.

[15] Dontsova, K.M., Pennington, J.C., Hayes, C., Simunek, J., Williford, C.M., "Dissolution and transport of 2,4-DNT and 2,6-DNT from M1 propellant in soil", Chemosphere, Volume: 77, Issue: 4, Publisher: Elsevier Ltd, Pages: 597-603, 2009.

[16] US Army Defense Ammunition Center, Logistic review and technical assistance office, Savanna, Illinois, 61074 9639, "Propellant Management Guide", June 1998. 